\title{
A Task Technology Fit Model on e-Learning
}

\author{
Linwu Gu, Indiana University of Pennsylvania, lgu@iup.edu \\ Jianfeng Wang, Indiana University of Pennsylvania,jwang@iup.edu
}

\begin{abstract}
In this research, we propose the development and examination of a theoretical model based on a task technology fit (TTF) on e-learning effectiveness and satisfaction. Measures of task complexity, self-efficacy, learning environment, task technology fit, learning satisfaction, and learning effectiveness were used in a university environment to collect 156 responses. Our study shows that task complexity, self-efficacy, and learning climate and task technology fit influence e-learning effectiveness and that task, individual and technology characteristics are important predictors on e-learning.
\end{abstract}

Keywords: e-Learning, Task Complexity, Self-Efficacy, Learning Climate

\section{INTRODUCTION}

Electronic education technology, also called e-learning, has become more and more important in our societal education systems, not just for students in all kinds and levels of schools but also for employees under training for different purposes in all industries and governments. E-learning systems provide high flexibility, richness and interactions. But the effectiveness and satisfaction though e-learning systems have yet to be explored and confirmed. Information system researchers have recently devoted considerable attention to e-learning in order to better understand web-based learning and training system [15, 18, 20, 25, 26].

In this research, we first identified task, individual, and technology characteristics as antecedents of e-learning outcomes. Secondly, we applied task technology fit to explain the effects of task complexity, self-efficacy, and learning climate on learning effectiveness and satisfaction. Finally, we explore how e-learning effectiveness and satisfaction may be limited by poor learning climate, lower self- efficacy, and high task complexity. The purpose of this research is to gain a better understanding of how task technology fit (TTF) may affect e-learning effectiveness and satisfaction.

\section{THEORY FOUNDATION AND RESEARCH MODEL}

Task complexity is based on the idea that users perceive less control over completing tasks [21]. Moreover, task complexity was found to lead worse outcomes on Internet-based decision support systems in the previous studies [15]. Self-efficacy belief influences individuals' pursuance when they encounter challenges [26]. Self-efficacy has been used to assess and predict the level of performance. The previous literature has suggested that self-efficacy can lead to overconfidence and reduce performance over time [19, 24]. Individuals lacking self-efficacy have difficulty completing the learning task, and have less learning effectiveness via system use [11, 25]. Moreover, learning climate is defined as one of technology characteristics to individuals engaged in using e-learning system [20]. Learning climate is found to provide collaboration platform [6] via offering information, communication and feedback through e-learning system [6, 18]. In addition, better e-learning technology supports better informative guidance, and finally affects learning outcomes [2]. In summary, more flexible e-learning climate, better selfefficacy, and lower task complexity can contribute to positive learning effectiveness and satisfaction via technology fit. 


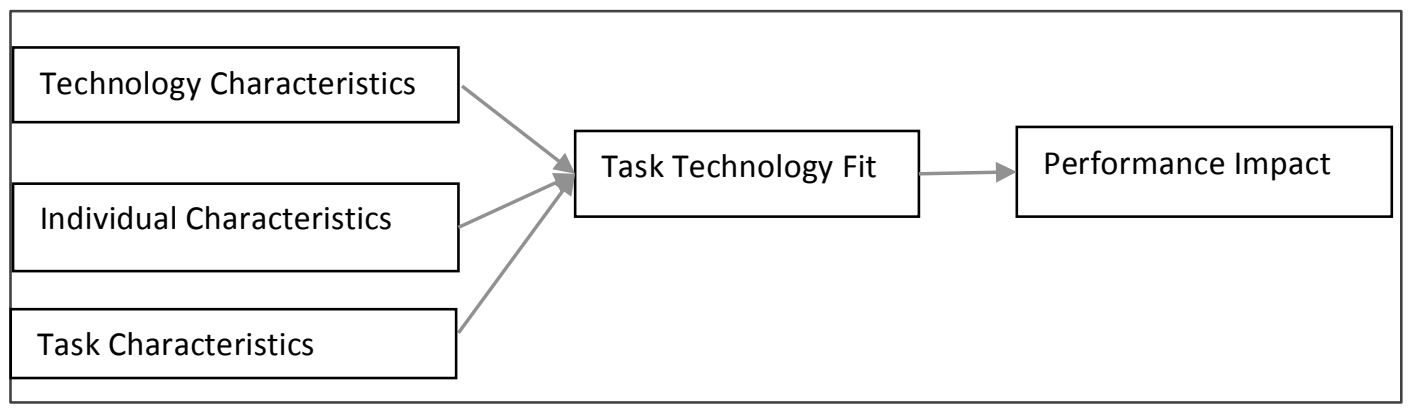

Figure 1. Task Technology Fit Model (TTF) by Goodhue and Thompson [10]

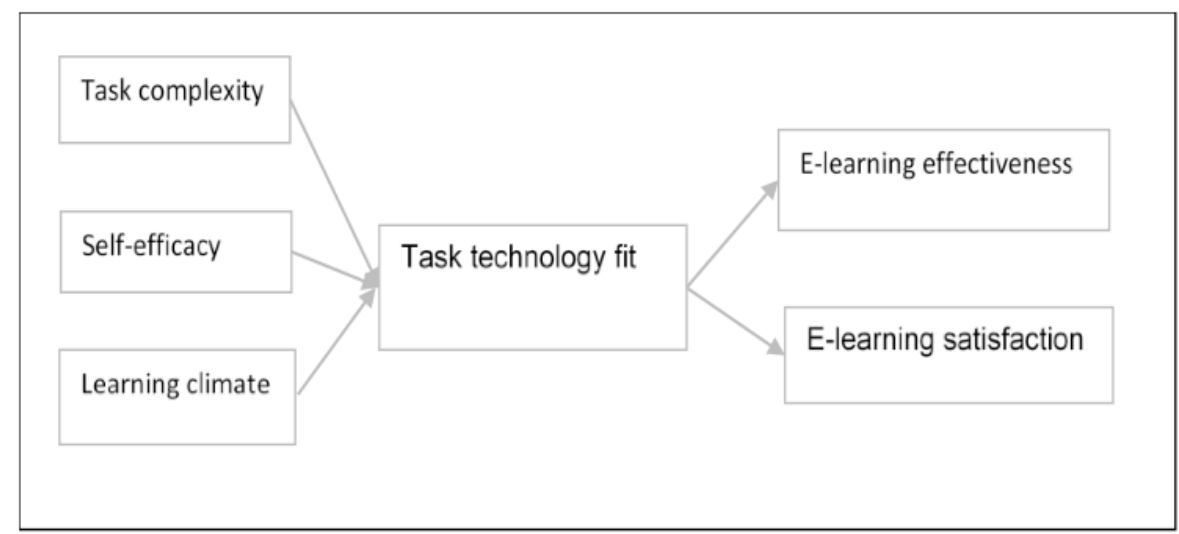

Figure 2. Model of Task Technology Fit (TTF) and E-learning Effectiveness and Satisfaction

The model of task technology fit (TTF) (Figure 1) suggests that a fit between the task, technology, and individual characteristics determines an individual's performance [10]. TTF explains that technology acceptance is related to how well the technology fits the task requirements, and is defined as the correspondence between task requests, individual characteristics, and the functionality of technology. In most previous studies, TTF measures the perceptions to which systems meet the requirements of a user's tasks and assists an individual in performing the tasks [12]. It is found that task technology fit affect user perceptions in a task setting, and report mixed findings for the performance effects of task [16].We employ the TTF concept, which explains the impacts of learning outputs at the individual level, task level, and technology level, as the fundamental indicators of our model.

As studied in previous research framework, e-learning performances are mediated through information and communication technologies [25]. However, little is done about task, individual, and technology effects on elearning results via technologies.

In our study, we examine how subjective task complexity, which relates to difficulty, ambiguity, and lack of clarity in the task using technology, can influence individual's performance. Task complexity affects uncertainty [21]. There may be a lack of control of informational influence on outcomes with complex tasks, which may further result in poor outcomes due to higher information processing [15].

Self-efficacy played a significant role in the learning process, and was an important factor on learning outcomes. Self-efficacy in e- learning environment describes an individual's belief to use information communication technologies and accomplish work tasks [22], and it is found to indicate the degree of an individual's willingness to make efforts on performance. Therefore, individuals who have high self-efficacy are more likely to make an effort to be effective, thus achieving better learning outcomes [3, 4]. In the previous studies, Indivuduals with high efficacy beliefs have a greater chance of success in a given task in a vitrtual environment [23]. 
Learning climate refers to the extent to which individuals taking online classes explore e- learning system tools and technology [7]. Learning climate has been identified as a useful perspective for understanding how an environment can affect individuals' willingness to explore a technology [2]. Positive learning climate reflects the extent to which individuals have perception of information sharing, autonomous action, responsibility, and accessible IT use [20].

Learning effectiveness has been measured in terms of students' learning. Meanwhile, there have been many studies of factors that influence learners' satisfaction, for example, one of previous studies examined the influence of technological characteristics on learners' satisfaction and other studies have examined the effect of learning tasks on satisfactions [8, 18]. Higher student satisfaction and effectiveness can be seen as the result of good learning [1, 18]. Overall, satisfaction and effectiveness has also been widely used as factors to evaluate learning performances.

According to the above literature reviews, we hypothesized as following (Figure 2):

$\mathrm{H}_{1}$ : Task complexity negatively influences task technology fit

$\mathrm{H}_{2}$ : Self efficacy positively influences task technology fit

$\mathrm{H}_{3}$ : learning climate positively influences task technology fit

$\mathrm{H}_{4}$ : Task technology fit mediates between task complexity and learning effectiveness

$\mathrm{H}_{5}$ : Task technology fit mediates between self- efficacy and learning effectiveness

$\mathrm{H}_{6}$ : Task technology fit mediates between learning climate and learning effectiveness

$\mathrm{H}_{7}$ : Task technology fit mediates between task complexity and learning satisfaction

$\mathrm{H}_{8}$ : Task technology fit mediates between self- efficacy and learning satisfaction

$\mathrm{H}_{9}$ : Task technology fit mediates between learning climate and learning satisfaction

\section{RESEARCH METHODOLOGY AND DATA ANALYSIS}

\section{Sample and Procedures}

Data were collected from 156 students who came from 4 online courses through 2 semesters. Each student was asked to take the survey for extra credits during the final week before they complete online course. Students were not allowed to repeat taking the survey in the different online courses.

\section{Instrument}

In order to test the proposed hypotheses, we used measurement items found in related studies [13, 17, 19, 20, 25, and 26] and modified them for the measures in this research. The scales and the questionnaire for the proposed hypotheses are shown in Appendix A. All measures were taken on seven-point Likert scales, from 1=strongly disagree to $7=$ strongly disagree (Appendix A)

\section{Confirmatory Factor Analysis}

Confirmatory factor analysis was used to test the measurement model for the reliability and the validity. We use confirmatory factor analysis to confirm convergent validity and discriminant validity. According to prior research, the perceptual measures should exceed 0.70 [9], we found the measurement model results with AVE values exceeding the recommended values (table 1). We also evaluate the discriminant validity using the square root of AVE for each construct which shows higher than the levels of correlations involving the construct (Table 2). 
Table 1. Descriptive Statistics and Convergent Validity Test

\begin{tabular}{|l|c|c|c|c|}
\hline \multicolumn{1}{|c|}{ Constructs } & $\begin{array}{c}\text { Number of } \\
\text { items }\end{array}$ & $\begin{array}{c}\text { Response } \\
\text { mean }\end{array}$ & $\begin{array}{c}\text { Average } \\
\text { variance }\end{array}$ & $\begin{array}{c}\text { Construct } \\
\text { reliability }\end{array}$ \\
\hline Task Complexity (TC) & 4 & 2.29 & 0.71 & 0.821 \\
Self- Efficacy (SE) & 4 & 5.27 & 0.65 & 0.706 \\
Learning Climate (LC) & 5 & 4.23 & 0.68 & 0.835 \\
Task Technology Fit (TTF) & 8 & 4.71 & 0.77 & 0.714 \\
E-Learning Effectiveness (ELE) & 5 & 5.76 & 0.82 & 0.732 \\
E-Learning Satisfaction (ELS) & 4 & 3.16 & 0.58 & 0.720 \\
\hline
\end{tabular}

Table 2. Discriminant Validity

(TC-Task Complexity, SE- Self Efficacy, LC-Learning Climate, TTF-Task Technology Fit, ELE-e Learning Effect, and ELS- e-Learning Satisfaction)

\begin{tabular}{|l|c|c|c|c|c|c|}
\hline Construct & TC & SE & LC & TTF & ELE & ELS \\
\hline TC & 0.842 & & & & & \\
\hline SE & 0.35 & 0.806 & & & & \\
\hline LC & 0.55 & 0.521 & 0.825 & & & \\
\hline TTF & 0.44 & 0.442 & 0.162 & 0.877 & & \\
\hline ELF & 0.35 & 0.411 & 0.192 & 0.238 & 0.906 & \\
\hline ELS & 0.38 & 0.622 & 0.331 & 0.325 & 0.262 & 0.762 \\
\hline
\end{tabular}

Table 3. Overall Model Fit Indices for the Research Model

\begin{tabular}{|l|l|l|}
\hline \multicolumn{1}{|c|}{ Model Fit Indices } & \multicolumn{1}{c|}{ Results } & \multicolumn{1}{c|}{ Recommended Value } \\
\hline Chi-square statistic x2/d.f & 2.1 & $<=3$ \\
\hline AGFI & 0.83 & $>0.80$ \\
\hline CFI & 0.92 & $>0.9$ \\
\hline NNFI & 0.96 & $>0.9$ \\
\hline RMSEA & 0.056 & $<0.08$ \\
\hline
\end{tabular}

\section{Model Testing Results}

The overall fit and the strengths of the hypothesized paths were examined. As shown in Table 3, the fit indices were within accepted thresholds: $\mathrm{Chi}-$ square statistic $=2.10, \mathrm{AGFI}=0.83, \mathrm{NNFI}=0.96, \mathrm{CFI}=0.92$ and RMSEA $=0.056$. Hence, this model fitted the data reasonably well, and the results were summarized in Table 4 . Task complexity $(\beta=$ $-0.35, p=0.07)$, self-efficacy $(\beta=0.16, p=0.02)$, and learning climate $(\beta=0.27, p=0.01)$ have significant effects on task technology fit. Therefore $\mathrm{H}_{1}, \mathrm{H}_{2}$, and $\mathrm{H}_{3}$ are supported.

A structural model using LISREL was run to check the influences from task complexity, self-efficacy, and learning climate on e-learning effectiveness and e-learning satisfaction. Task complexity, self-efficacy and learning climate have significant influences on e-learning effectiveness with p-values smaller than 0.05 and $\beta$ values for task complexity, self-efficacy and learning climate at $-0.58,0.62$, and .43 . Task complexity, self-efficacy and learning climate do not show significant influences on e-learning satisfaction with p-vales all bigger than 0.1 .

The relationship between task technology fit and e-learning effectiveness was also found significant ( $\beta=0.13$, $\mathrm{p}=0.04)$. There is no significant relationship between task technology and e-learning satisfaction $(\beta=0.13, \mathrm{p}=0.72)$. According to Baron and Kennedy (1986), none of $\mathrm{H}_{7}, \mathrm{H}_{8}$, and $\mathrm{H}_{9}$ is supported [5]. 
We ran a structural analysis by adding task technology fit as a mediating factor into the mode as depicted in Figure 2 . The impacts from task complexity, self-efficacy, and learning climate on e- learning effectiveness were reduced when the mediator, the task technology fit was added into the model. Beta-values for task complexity, self-efficacy, and learning climate are $-0.34, .31$, and .16 . Therefore, the mediating effects of task technology fit between task complexity, learning climate, and self-efficacy on e-learning effectiveness are significant [5].

Table 4. Results of Hypothesis Testing

\begin{tabular}{|c|c|}
\hline Hypotheses & Results \\
\hline $\begin{array}{l}\mathrm{H}_{1} \text { Task complexity negatively influences } \\
\text { task technology fit }\end{array}$ & $\begin{array}{l}\text { Supported } \\
\beta=-0.35, p=0.07\end{array}$ \\
\hline $\begin{array}{l}\mathrm{H}_{2} \text { : Self efficacy positively influences task } \\
\text { technology fit }\end{array}$ & $\begin{array}{l}\text { supported } \\
\beta=0.16, p=0.02\end{array}$ \\
\hline $\begin{array}{l}\mathrm{H}_{3} \text { : learning climate positively influences } \\
\text { task technology fit }\end{array}$ & $\begin{array}{l}\text { Supported } \\
\beta=0.27, p=0.01\end{array}$ \\
\hline $\begin{array}{l}\mathrm{H}_{4}: \text { task technology fit mediate between task } \\
\text { complexity and e-learning effectiveness }\end{array}$ & \multirow[t]{3}{*}{$\begin{array}{l}\text { Supported because there is significant relationship } \\
\text { between task technology fit and e-learning } \\
\text { effectiveness and }\end{array}$} \\
\hline $\begin{array}{l}\mathrm{H}_{5} \text { : task technology fit mediate between self- } \\
\text { efficacy and e-learning effectiveness }\end{array}$ & \\
\hline $\begin{array}{l}\mathrm{H}_{6}: \text { task technology fit mediate between } \\
\text { learning climate and e-learning effectiveness }\end{array}$ & \\
\hline $\begin{array}{l}\mathrm{H}_{7} \text { : task technology fit mediate between task } \\
\text { complexity and e-learning satisfaction }\end{array}$ & \multirow[t]{3}{*}{$\begin{array}{l}\text { Not supported } \\
\text { Because there is no significant relationship between } \\
\text { task technology fit and e-learning satisfaction }\end{array}$} \\
\hline $\begin{array}{l}\mathrm{H}_{8} \text { : task technology fit mediate between self- } \\
\text { efficacy and e-learning satisfaction }\end{array}$ & \\
\hline $\begin{array}{l}\mathrm{H}_{9} \text { : task technology fit mediate between } \\
\text { learning climate and e-learning satisfaction }\end{array}$ & \\
\hline
\end{tabular}

\section{CONCLUSIONS AND LIMITATIONS}

Our study was designed to gain a better understanding of e-learning and task technology fit. Our study shows that task complexity, self-efficacy, and learning climate and task technology fit influence e-learning effectiveness. In addition, our findings also suggested that task, individual and technology characteristics are important predictors on e-learning. The findings help us better understand task technology fit and learning outcomes, and should benefit elearning developers and designers. Although the findings are useful, our study had several limitations. First, we examined online class using only D2L. And the subjects were just college students, and self-efficacy measures were collected at the end of online courses, and it might affect the results. For organizations and institutions that are considering growing their e-learning programs, different levels of task complexity and various functionality of learning environment may result in diminished learning effectiveness. Some other factors about task technology and task might be explored in the future studies.

\section{REFERENCES}

1. Alavi, M. (1994). Computer-Mediated Collaborative Learning: An Empirical Evaluation. MIS Quarterly, 18(2), $159-174$.

2. Amabile, T. M., Conti, R., Coon, H., Lazenby, J., \& Herron, M. (1996). Assessing the Work Environment for Creativity. Academy of Management Journal, 39(5), 1154-1184. 
3. Bandura, A. (1977). Toward a unifying theory of behavioral change. Psychological Review, 84, 191-215.

4. Bandura, A. (2001). Social Cognitive Theory: A Gentic perspective. Annual Review of Psychology, 52, 1-26.

5. Baron, R., \& Kenny, D. (1986). The moderator-mediator variable distinction in social Psychological research: Conceptual, strategic, and statistical considerations. Journey of Personality and Social Psychology, 51(6), 1173-1182.

6. Bock, G., Zmud, R., Kim, Y., \& Lee, J. (2005). Behavioral intention dormation in knowledge sharing: Examining the roles of extrinsic motivators. Social-psychological forces, and organizational climate. MIS Quarterly, 29(1), 87-111.

7. Edmondson, A. C. (1999). Psychological safety and learning behavior in work teams. Administrative Science Quarterly, 44(2), 350-383.

8. Carswell, A. D., \& Venkatesh, V. (2002). Learner outcomes in an asynchronous distance education environment. International Journal of Human-Computer Studies, 56, 475-494.

9. Fornell, C., \& Larcker, D. (1981). Evaluating structural equation models with unobservable and measurement error. Journal of Marketing Research, 18(1), 39-50.

10. Goodhue, D., \& Thompson, R. (1995). Task-technology fit and individual performance. MIS Quarterly 19(2), 213-236.

11. Gravill J., \& Compeau, D. (2008). Self-regulated learning strategies and software training. Information \& Management, 45(5), 288-296.

12. Im, G. (2014). Effects of cognitive and social factors on system utilization and performance outcomes. Information \& Management, 519, 129 -137.

13. Jarupathirun, S., \& Zahedi, F. (2007). Exploring the influence of perceptual factors in the success of webbased spatial DS. Decision Support Systems, 43, 933-951.

14. Lankton, N., Wilson, E., \& Mao, E. (2010). Antecedents and determinants of Information Technology habit. Information \& Management, 47, 300-307.

15. Lankton, N., Speier, C., \& Wilson, V. (2012). Internet-based knowledge acquisition: Task complexity and performance. Decision Support Systems, 53, 55-65

16. Liu, Y., Lee, Y., \& Chen, N. (2011). Evaluating the effects of task-individual-technology fit in Multi-DSS Models context: A two-phase view. Decision Support Systems, 51(3), 688-700.

17. Low, G., \& Mohr, J. (2001). Factors affecting the use of information in the evaluation of marketing communications productivity. Journal of the Academy of Marketing Science 29(1), 70-88.

18. Lu, J., \& Yu, C. Chang, L. (2003). Learning style, learning patterns, and learning performance in a WebCTbased MIS course. Information \& Management, 40, 497-507.

19. Limayem, M., Hirt, S., \& Cheung C., (2007). How habit limits the predictive power of intention: The case of Information Systems continuance. MIS Quarterly, 31(3), 1-33.

20. Maruping, L., \& Magni, M. (2012). What's the weather like? The effect of team learning climate. Empowerment climate and gender on individuals' technology exploration and use. Journal of Management Information Systems, 29(1), 79-113.

21. Rosander, M., \& Eriksson, O. (2012). Conformity on the Internet: The role of task difficulty and gender differences. Computers in Human Behavior, 28, 1587-1595

22. Staples, D., Hulland, J., \& Higgins, C. (1999). A self- efficacy theory explanation for the management of remote workers in virtual organizations. Organization Science, 10(6), 758-886.

23. Torkzadeh, G, Chang, J., \& Demirhan, D. (2006). A contingency model of computer and Internet self efficacy. Information \& Management, 43, 541-550.

24. Moores, T., \& Chang, C. (2009). Self-efficacy, overconfidence, and the negative effect on subsequent performance: A field study. Information \& Management, 46, 69-76.

25. Wan, Z., Wang, Y., \& Haggerty, N. (2008). Why people benefit from e-learning differently: The effects of psychological processes on e-learning outcomes. Information \& Management, 45, 513-521.

26. Wang, Y., \& Haggerty, N. (2011). Individual virtual competence and its influence on work outcomes. Journal of Management Information Systems, 27(4), 299-333 


\section{APPENDIX A}

\section{Task complexity from [17]}

[Performing activity] is

(1) Easy/difficult

(2) Clear/ambiguous

(3) Straightforward/ill-structured

(4) Simple/complicated

\section{Self-efficacy (modified from [26])}

(1) I have confidence that I can complete my online course because I can access appropriate support staff readily

(2) I have confidence that I can complete my online course because I can access information needed to perform my job

(3) I have confidence that I can complete my online course because I can set objectives that align with the organization's goals

(4) I have confidence that I can complete my online course because I can prioritize tasks to use my time effectively

\section{Learning climate (modified from [20])}

(1) In this course, errors are considered a source of learning.

(2) In the course, it is easy to communicate with instructor and get feedback.

(3) My course makes its lessons learned available to all students

(4) In the course, individuals revise their thinking as a result of class discussion or information collected.

(5) In the course, course information resources are available and useful.

\section{Perceived learning effectiveness [25]}

(1) I learned to identify central issues of the course

(2) I learned to inter-relate important issues of the course

(3) I developed the ability to communicate clearly about the subject

(4) I improved my ability to integrate facts and develop generalizations from the course material

\section{Satisfaction from [19]}

I am — with my use of e- learning system for [performing activity]

(1) Very displeased/very pleased

(2) Frustrated/contented

(3) Miserable/delighted

(4) Dissatisfied/satisfied

\section{Perceived task technology fit [13]}

(1) Very inadequate vs. Very adequate

(2) Very inappropriate vs. Very appropriate

(3) Not useful at all vs. Very useful

(4) Very incompatible with the task vs. Very compatible with the tlask

(5) Not helpful at all vs. Very helpful

(6) Not sufficient at all vs. Very sufficient

(7) Did not made the task easy at all vs. Made the task very easy

(8) In general, did not fit the task at all vs. Best fit the task 